Clemente Pignatti ${ }^{1,2, *}$ and Eva Van Belle $e^{3,4}$

\title{
Better together: Active and passive labor market policies in developed and developing economies
}

\begin{abstract}
We investigate the macroeconomic impact of public expenditure in active labor market policies (ALMPs) and passive labor market policies (PLMPs) on main employment indicators (i.e., unemployment, employment, and labor force participation) for a large and novel panel database of 121 countries (36 developed, 64 emerging and 21 developing economies). Compared to previous studies, we include for the first time evidence from developing and emerging economies and explicitly examine the possible presence of complementarities between active and passive policies. We find that the interaction between interventions is crucial, as the effect of spending in either of the two policies is more favorable the more is spent on the other. Even the detrimental labor market effects of passive policies disappear on the condition that sufficient amounts are spent on active interventions. This complementarity seems even more important for emerging and developing economies.
\end{abstract}

Current version:

Keywords:

JEL codes:

Corresponding author:
February 07, 2021

developing countries, evaluation, labor economics, public policy, welfare state

J08 Labor Economics Policies, E24 Employment; Unemployment; Wages; Intergenerational Income Distribution; Aggregate Human Capital; Aggregate Labor Productivity, 01 Economic Development

Clemente Pignatti

pignatti@ilo.org

\footnotetext{
1 International Labour Organization, Route des Morillons 4, 1211 Genève

2 Geneva School of Economics and Management, University of Geneva, rue du Général-Dufour 24, 1211 Genève

3 Swiss Forum for Migration and Population Studies (SFM), Université de Neuchâtel, 2000 Neuchâtel, Switzerland

4 Department of Economics, Ghent University, 9000 Ghent, Belgium
}

(C) The Author(s). 2021. Open Access This article is distributed under the terms of the Creative Commons Attribution 4.0 International License (http://creativecommons.org/licenses/by/4.0/), which permits unrestricted use, distribution, and reproduction in any medium, provided you give appropriate credit to the original author(s) and the source, provide a link to the Creative Commons license, and indicate if changes were made. (9) Cite as: Pignatti and Van Belle. IZA Journal of Development and Migration (2021) 12:09 


\section{Introduction}

The rise in unemployment in developed economies during the 1980s led governments to increasingly use the coordination of passive labor market policies (PLMPs) and active labor market policies (ALMPs) to offer social protection, while at the same time enhancing the transition from unemployment to employment (Estevão, 2003; ILO, 2014). This policy trend regained a central stage since the eruption of the global financial crisis in 2008, which reinforced the need for governments to channel spending toward interventions that could at the same time protect workers' income and raise their employability (Martin, 2015). While ALMPs have a long history in Organisation for Economic Cooperation and Development countries, at the beginning the potential linkages between the generosity of the unemployment benefits, the size and composition of ALMPs, and the degree to which unemployment benefits' eligibility was determined by participation in ALMPs were largely ignored (ibid). Indeed, it was believed that to activate the unemployed, public spending needed to shift from PLMPs to active interventions (OECD, 1994). However, evidence showed that countries implementing this strategy did not automatically improve their labor market performance, suggesting that active and passive policies should be seen as two essential components of a broader social protection system (ILO, 2012, 2019).

In emerging and developing economies, social protection systems were originally implemented as short-term interventions in response to crises and structural adjustments (Barrientos, 2010; McCord, 2012; Sabates-Wheeler and Devereux, 2011). However, rising poverty and stagnating productivity following the 1980s' "lost decade" in Latin America, the financial crises in Asia in the 1990s, and rapid economic transformation in transition economies demonstrated the need for strong and stable labor market institutions concerned with poverty reduction and employment promotion (Barrientos, 2010; McCord, 2012). This led to two parallel developments. On the one hand, there has been a marked increase in conditional cash transfers and public works programs aiming to tackle basic income security (Barrientos and Hulme, 2009). ${ }^{1}$ On the other hand, social protection has become increasingly linked to other measures (i.e., skills programs). These social protection systems serve not only the present basic income security role, but also aim to increase the opportunities to improve capabilities and break the poverty cycle (DFID, 2011). At the same time, ALMPs in emerging economies are rarely promoted as independent interventions (i.e., without a connection with income support programs) (ILO, 2016).

Despite this increased policy interest, very few studies have taken a macroeconomic approach to the assessment of active and passive interventions (and their possible complementarity) - and the existing studies (as reviewed in Section 2) focus exclusively on OECD countries. The current study complements the existing macroeconomic literature by expanding the analysis to several emerging and developing economies. In particular, we look at data from 121 countries - of which 85 are not classified as developed economies. ${ }^{2}$ Given differences in the functioning of labor markets as well as differences in the way in which labor market policies are implemented between developed on the one hand, and emerging and developing economies, on the other, results from previous studies cannot be easily generalized to

1 In line with the horizontal dimension of the ILO recommendation on social protection (ILO 2012), i.e., the implementation of a social protection floor.

2 The paper follows the World Bank classification between developed, emerging, and developing economies as of 2017. 
non-developed economies. For instance, the general concern over the possible presence of disincentive effects generated by passive policies might not equally apply in the context of developing economies - where the risk of out-of-work poverty is particularly high. At the same time, ALMPs and PLMPs operate in largely informal labor markets in emerging and developing economies and they often do not adequately interact with other types of public interventions (e.g., education systems) - potentially limiting their reach and effectiveness (ILO, 2019).

Furthermore, this paper explicitly takes the interaction between ALMPs and PLMPs into account and tests for its effect on labor market outcomes. ${ }^{3}$ Indeed and as discussed above, active and passive policies are often coordinated (if not jointly implemented) and they can simultaneously target the same individuals in the labor market. Therefore, specifications that do not consider this interaction likely suffer from omitted variable bias. At the same time, previous studies examining this complementarity have mostly done so to explore whether the potentially detrimental effects of PLMPs (e.g., reduced job-search efforts) might be alleviated through higher spending in ALMPs. We approach the debate from an agnostic point of view, to understand whether both active and passive policies can be more effective if the other type of intervention is adequately financed. This shift in the approach is particularly important given the new set of countries at the center of the analysis. Indeed and while ALMPs often include an income support component in emerging and developing economies, the explicit coordination of active and passive policies is more frequent in developed economies.

The results reveal that ALMPs alone increase job-search efforts (i.e., reduce unemployment rates) while PLMPs alone have the anticipated disincentive effects (i.e., reduce employment rates). However, when also taking the interaction between active and passive policies into consideration, a different picture emerges. In particular, each type of (active or passive) intervention is more effective if spending in the other type increases. As a result, even the negative effect of PLMPs disappears for a given level of spending in ALMPs. These findings hold both in developed and developing and emerging economies, but the complementarity between policies seems even more important in improving labor market outcomes in developing and emerging than in advanced economies.

The rest of the paper is structured as follows. Section 2 gives an overview of the existing micro- and macroeconomic literature. Section 3 describes the data sources and provides insights into the data gathering process. The main trends in spending in ALMPs and PLMPs are presented in Section 4. Section 5 describes the empirical strategy adopted, while Section 6 reports the main results and the robustness tests for the overall sample. The results by country grouping will be presented in Section 7; while Section 8 discusses the results obtained in the paper as well as their policy implications. Finally, Section 9 concludes.

\section{Review of the Literature}

The increased importance of active labor market and income support policies in both developed and emerging economies since the 1980s have generated interest by researchers in evaluating their

3 While we cannot directly examine the effectiveness of the joint implementation of active and passive interventions at the level of the single policy initiative, we look at whether overall ALMPs and PLMPs generate more beneficial effects at the macroeconomic level when enough is spent in the other type of intervention. 
effectiveness (Greenberg et al, 2003; Heckman et al., 1999; Kluve, 2010; Van Belle et al., 2019). While most evaluations look at the effects of one specific intervention, few studies have looked at the combination of active and income support policies. For developed economies, the microeconomic evidence is rather mixed. Overall, results suggest that - after an initial lock-in period both the job-finding rate and the quality of the employment increase due to the policy mix (Bolhaar et al., 2019; Crépon et al., 2012; Graversen and Van Ours, 2008; Markussen and Røed, 2016; Pastore et al., 2021). Nevertheless, some studies find no or adverse effects on labor market outcomes (Cockx and Van Belle, 2019; McGuiness et al., 2019). For emerging and developing economies, this sounds weird to me. While positive results on employment and income were found for programs combining cash transfers and training in Nicaragua and Chile (Macours et al., 2012; Martínez et al., 2015) and a program combining public works and training in Bangladesh (Hashemi and Rosenberg, 2006) similar programs appeared to produce adverse effects in Argentina (Galasso et al., 2004; Almeida and Galasso, 2010) and Uruguay (Escudero et al., 2020). Moreover, a program combining an employment subsidy with training in Colombia led to a decrease in employment 18 months after participation (Medina et al., 2013).

While this evidence is quite rich, very few studies have taken a macroeconomic approach to the assessment of active and passive interventions. This relates to general problems of econometric identification in cross-country analyses as well as the lack of adequate information on spending in passive and active policies beyond OECD economies. Filling this void is particularly important, as macroeconomic studies can address critical questions such as the presence of general equilibrium effects (e.g., disincentives or displacement effects) that are generally not taken into account in single impact evaluations. Similarly, cross-country analyses can generate conclusions who are valid beyond the single intervention at the center of the impact evaluation. Accordingly, several studies have looked at the effectiveness of spending in ALMPs in developed economies, sometimes controlling for the level of unemployment benefits. Escudero (2018) examines the effect of spending in ALMPs in OECD countries and finds that they can improve employment outcomes (especially for low-skilled individuals). Gal and Theising (2015) look both at unemployment insurance (UI) benefit replacement rates and spending in ALMPs and find that both lower UI replacement rates and higher spending in ALMPs increase employment. A similar conclusion is reached by Estevão (2003); while Hujer et al. (2009) find no effect of ALMPs on the matching process in West Germany. Another strand of literature looks at the macroeconomic effects of labor market institutions and reforms - of which both ALMPs and UI are important components. The studies by Blanchard and Wolfers (2000), Murtin and de Serres (2014), and Murtin and Robin (2018) confirm that additional spending in ALMPs increases employment, while a higher UI replacement rate has the opposite effect. Some of these studies have also explored the possible interaction between active and passive interventions. For instance, Bassanini and Duval $(2006,2009)$ find that the adverse impact of the generosity of UI is lower in countries that spend more on ALMPs. Boone and van Ours (2004) estimate the same interaction but with specific types of ALMPs and find that spending in training is more effective for countries with a more generous UI. Elmeskov et al. (1998) find an inverted U-shape relationship between the detrimental effects of UI and spending in ALMPs (i.e., with the negative effects of UI being the lowest in countries with an average amount of spending in ALMPs). 
In summary, the existing macroeconomic literature finds that - for OECD countries increased spending in ALMPs has a positive effect on employment outcomes, while more generous UI benefits have detrimental effects on employment outcomes. Moreover, those studies that take the interaction between both types of policies into account provide evidence for potential complementarities. In what follows, we extend this literature by including - for the first time evidence from non-OECD countries.

\section{Data Sources and Descriptive Statistics}

We construct a novel panel database of ALMPs and PLMPs combining data from different sources, countries, and time periods. Our final database comprises also data on labor market outcomes, policy expenditures, Gross domestic product skill composition, and government expenditures from 121 countries, from 1985 to 2016. In what follows, we provide an in-depth presentation of the source of each of these time series.

Following previous studies, we look at three main outcomes of interest to capture the effects of labor market policies on employment dynamics: the unemployment rate, the employment-to-population ratio, and the labor force participation rate. All this information is gathered from the ILO World Economic and Social Outlook (WESO) database, which produces harmonized series for 189 countries from $1991 .{ }^{4}$

The main regressors of interest in our model are the variables capturing the intensity of ALMPs and PLMPs. While different options are available, we look at spending in ALMPs and PLMPs as a percentage of GDP. As Estevão (2003) argues, using this measure may downward bias the results as aggregate output shocks change unemployment in the same direction as spending in labor market policies as a share of GDP. Therefore, the final estimates should be interpreted as a lower bound for the true effect of labor market policies on employment outcomes. Other studies alternatively use the spending per unemployed individual (Escudero, 2018; Gal and Theising, 2015; Murtin and de Serres, 2014; Murtin and Robin, 2018), as this might be seen as more representative of the true policy stance (Escudero, 2018). Nevertheless, we believe that the first measure of policy intensity (i.e., spending as a share of GDP) is the most appropriate one in this study for two reasons. First, we include different labor market policies, including those targeted towards individuals who already have a job or that outside of the labor market (e.g., labor market services and unemployment assistance). As a result, dividing the total spending in these labor market policies by the number of unemployed individuals would overestimate treatment intensity for a single individual. Second, we include a large number of countries with very different levels of both government expenditure and GDP - while the number of unemployed individuals might be more similar across countries. We argue that it is important to take these different levels of GDP into account to have a realistic measure of the policy intensity.

The OECD defines expenditure in ALMPs as all expenditure aimed at improving the beneficiaries' prospect of finding gainful employment. This includes spending in (i) public employment services and administration; (ii) training; (iii) employment incentives; (iv)

4 While we tried to cover additional dimensions of employment quality (e.g., working poverty, informality), in practice this data is not available for the large majority of the countries in our sample. In this context, we give priority to covering relatively more countries along dimensions that have already been explored. 
sheltered and supported employment; (v) direct job creation; and (vi) start-up incentives. Of course, the structure and content of ALMPs differ between developed and emerging and developing economies; with such a clear categorization not often applying in the latter group where ALMPs tend to combine different components (ILO, 2016). Spending in PLMPs on the other hand consists of spending in (i) UI; (ii) unemployment assistance; and (iii) programs for early retirement (OECD, 2007). Even in this case, such a clear-cut differentiation does not often apply in emerging and developing economies; where income support programs tend to target the most vulnerable groups in the population without a strict labor market conditionality.

Given the broad geographical coverage of the present study, data on public expenditure in ALMPs and PLMPs is collected from different sources. Firstly, data for OECD countries comes from the OECD Labor Market Programs database. This database contains information on spending in ALMPs and PLMPs for 34 countries from 1985 to 2016 except some (mainly Eastern-European) countries - for which the information is available for a more limited time period. Secondly, data for EU member states who are not part of the OECD is collected from the Eurostat Labor Market Policy database. This gives us information for an additional five countries from 1985 to 2016, with some exceptions. Data from Eurostat and the OECD are fully comparable (i.e., we can compare the information for EU countries in the OECD from the two databases) and therefore the use of different data sources does not generate any inconsistency. Thirdly, we obtained access to detailed data on spending in active and passive labor market programs in 55 emerging and developing economies from the World Bank The Atlas of Social Protection Indicators of Resilience and Equity Database. This data source overlaps with data from the OECD and Eurostat for several countries. ${ }^{5}$ Unfortunately, the information is not fully comparable and for those countries, we use OECD data since it reports a longer time series. Fourthly and finally, data from 27 Asian countries was collected from the Social Protection Index (SPI) database from the Asian Development Bank (ADB). Data is mainly available for countries in Central, East, and South-East Asia from 2008 to 2015. In contrast with the other data sources, the data on PLMPs is limited to spending on UI. Again, data from ADB overlaps for two countries (Japan and Korea) with the OECD database and we opt for the latter source for the longer and more complete information. The lack of comparability between the data collected from different sources clearly represents a cause of concern and it could be due to several factors. First, the data reported in the World Bank ASPIRE Database only takes central government expenditures into account. Secondly, definitions of active and passive policies are also different across data sources. For example, while the OECD and ASPIRE data on PLMPs includes spending in early retirement benefits, this is not the case for the ADB data. Table A1 in Appendix gives an overview of the available data and their respective sources.

For the estimation strategy, we also extract information on GDP growth rates (from the World Economic Outlook Database of the IMF), on employment by skills' group (i.e., low, medium, and high skilled -from the ILO WESO database) and on the governments' primary balance (also from the World Economic Outlook Database of the IMF). Table 1 gives the descriptive statistics for the year 2010 for the outcome variables, the main regressors, and the

5 Bulgaria, Chile, Croatia, Czech Republic, Estonia, Hungary, Latvia, Lithuania, Mexico, Poland, Romania, Slovakia, and Slovenia. 
Table 1. Descriptive statistics (2010)

\begin{tabular}{|c|c|c|c|c|c|c|}
\hline & \multicolumn{2}{|c|}{ Overall } & \multicolumn{2}{|c|}{$\begin{array}{c}\text { Emerging and } \\
\text { developing } \\
\text { economies }\end{array}$} & \multicolumn{2}{|c|}{$\begin{array}{l}\text { Developed } \\
\text { economies }\end{array}$} \\
\hline & $\mathbf{N}$ & Mean & $\mathbf{N}$ & Mean & $\mathbf{N}$ & Mean \\
\hline \multicolumn{7}{|l|}{ A. Outcome variables } \\
\hline Unemployment rate & 121 & 0.080 & 85 & 0.076 & 36 & 0.090 \\
\hline Employment rate & 121 & 0.584 & 85 & 0.599 & 36 & 0.548 \\
\hline Labor force participation rate & 121 & 0.633 & 85 & 0.646 & 36 & 0.601 \\
\hline \multicolumn{7}{|l|}{ B. Main regressors } \\
\hline Spending in ALMPs (\% GDP) & 104 & 0.4832737 & 190 & 0.1215296 & 613 & 0.5953967 \\
\hline Spending in PLMPs (\% GDP) & 803 & 0.8125800 & 190 & 0.1605833 & 613 & 0.943 \\
\hline \multicolumn{7}{|l|}{ C. Control variables } \\
\hline Primary balance & 120 & -1.801 & 84 & -1.055 & 36 & -3.544 \\
\hline GDP growth gap & 121 & 0.034 & 85 & 0.046 & 36 & 0.005 \\
\hline Share in low-skill employment & 121 & 0.149 & 85 & 0.170 & 36 & 0.100 \\
\hline Share in medium-skill employment & 121 & 0.628 & 85 & 0.680 & 36 & 0.505 \\
\hline Share in high-skill employment & 121 & 0.223 & 85 & 0.151 & 36 & 0.395 \\
\hline
\end{tabular}

Note: The variables are defined as described in Section 3. The number of observations and means are calculated for the year 2010, where the data are available.

ALMPs, active labor market policies; PLMPs, passive labor market policies.

control variables in Panel A, Panel B, and Panel C, respectively. The descriptive statistics are provided both for the entire sample and by development status. Here and in the rest of the analysis, we pool together developing and emerging economies to have a relatively similar number of observations concerning labor market policies. It is important to note that the length of the time series is different across countries (i.e., with generally longer series available for developed economies). We, therefore, report the descriptive statistics for 2010, the year for which most data is available.

A first interesting observation is that - in 2010 - the unemployment rate was higher in developed economies. At the same time, the employment and labor force participation rates were slightly higher in emerging and developing economies. This can be explained by the fact that the lack of social protection in emerging economies makes open unemployment unaffordable. Rather than becoming unemployed, these individuals take up various forms of, often vulnerable, employment. Moreover, from the observations in Panel B of Table 1, it is clear that emerging and developing economies spend far lesser parts of their GDP in both ALMPs and PLMPs. However, we have to bear in mind that the expenditure data sourced from different databases is not fully comparable - and the empirical analysis will exploit this inconsistency. Lastly, Panel C gives the descriptive statistics for the control variables. In particular, the output gap seems to be more favorable for emerging and developing economies and the primary balance was more negative in developed economies - but both groups of countries reported on average a budget deficit. Finally, employment was relatively more concentrated in high skills occupations in developed economies compared to emerging and developing economies. 


\section{Labor Market Policies Across Regions}

Due to the lack of data from emerging and developing economies, little is known about the use of ALMPs and PLMPs outside of OECD countries. ${ }^{6}$ Here, we will exploit our novel comprehensive dataset to examine in more detail the trends in spending in ALMPs and PLMPs across geographical regions - irrespective of the development classification of the country - to provide descriptive evidence of policy trends. Nevertheless, some caveats need to be kept in mind. First and as mentioned above, data comes from different sources (even within the same region) so that they are not necessarily comparable and this will affect both the descriptive analysis presented in this Section as well as the econometric results discussed below. Secondly, data availability across countries changes significantly over time (with most developing and emerging economies having data points only after 2000). To alleviate these issues and make the descriptive analysis more comparable, in this descriptive Section we do not group together data from different sources, but rather report both figures separately for each of the four data sources. For this reason, comparisons can be made across regions within the same panel but not necessarily across regions presented in different panels.

With this in mind, Figure 1 presents the average spending in ALMPs and PLMPs across regions. It is important to bear in mind that one single data source is used for any country (i.e., even when the country has data from multiple sources, see discussion in Section 3 on how the relevant source was selected). This means that if data for the same region is reported

Figure 1. Average spending in ALMPs and PLMPs across regions as a share of GDP.

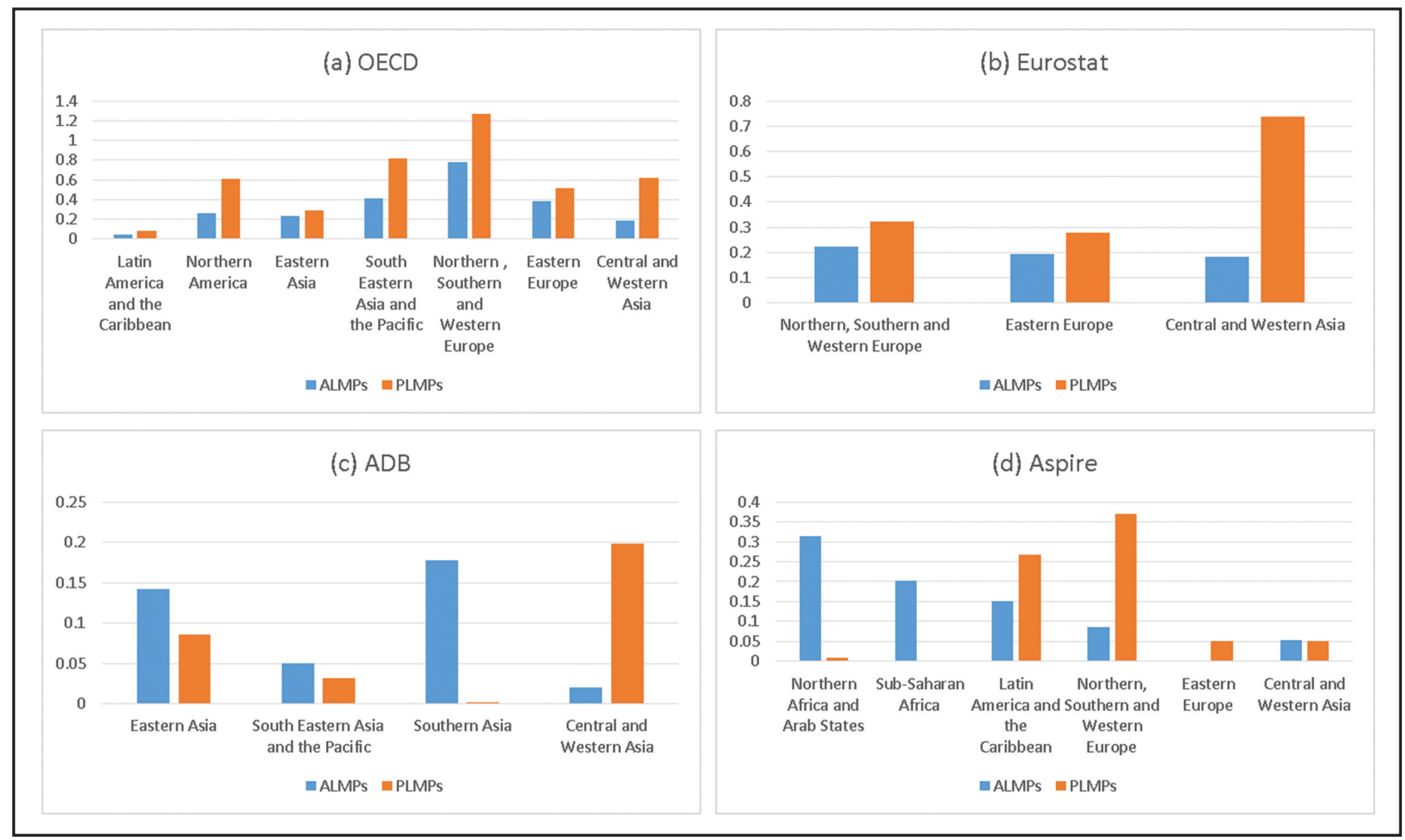

Note: Authors' calculations based on different data sources as reported in Section 2. ALMPs, active labor market policies; ADB, Asian Development Bank; PLMPs, passive labor market policies.

6 See Auer et al. (2008) for an early comprehensive overview of trends in ALMPs across regions. For detailed trends in Latin America and the Caribbean please refer to ILO (2016). 
in different panels (i.e., corresponding to different data sources), the countries included in the region will be different and therefore the data should not be necessarily comparable. Within the OECD countries (Panel A), the pattern that emerges is that spending in both active and passive policies is substantially higher in Northern, Western, and Southern European countries than in any other geographical regions - with average spending values equal to $0.8 \%$ of GDP for ALMPs and 1.3\% of GDP for PLMPs. Other regions present instead more limited and diversified spending patterns. Moreover, spending in PLMPs is consistently higher than spending in ALMPs. This is generally due to both higher coverage and the per capita cost of PLMPs. For the EU countries that are not in the OECD (Panel B), spending in ALMPs is relatively similar, while Cyprus (i.e., the only Eurostat country in Central and Western Asia) spends substantially more in PLMPs than the countries in the other regions. Differences are more pronounced when looking at the ADB data (Panel C). Spending in ALMPs is higher for countries in Eastern and Southern Asia, while countries in Central and Western Asia spend more on PLMPs. This is also the only region within the ADB database where spending in PLMPs is more important than spending in ALMPs. Finally, looking at the data from the ASPIRE database (Panel D), we see that countries in Northern Africa and the Arab States spend the most in ALMPs, followed by Sub-Saharan Africa and Latin America, and the Caribbean. Spending in PLMPs is most important in Northern, Southern, and Western Europe and Latin America and the Caribbean, while for the other regions, spending in PLMPs is almost non-existent.

We also look at the evolution of spending levels across regions over time. For ease of exposition, we look at the average over decades since the 1990s (Figure 2). The latest decade includes

Figure 2. Spending in ALMPS and PLMPs over regions and decades as a share of GDP.

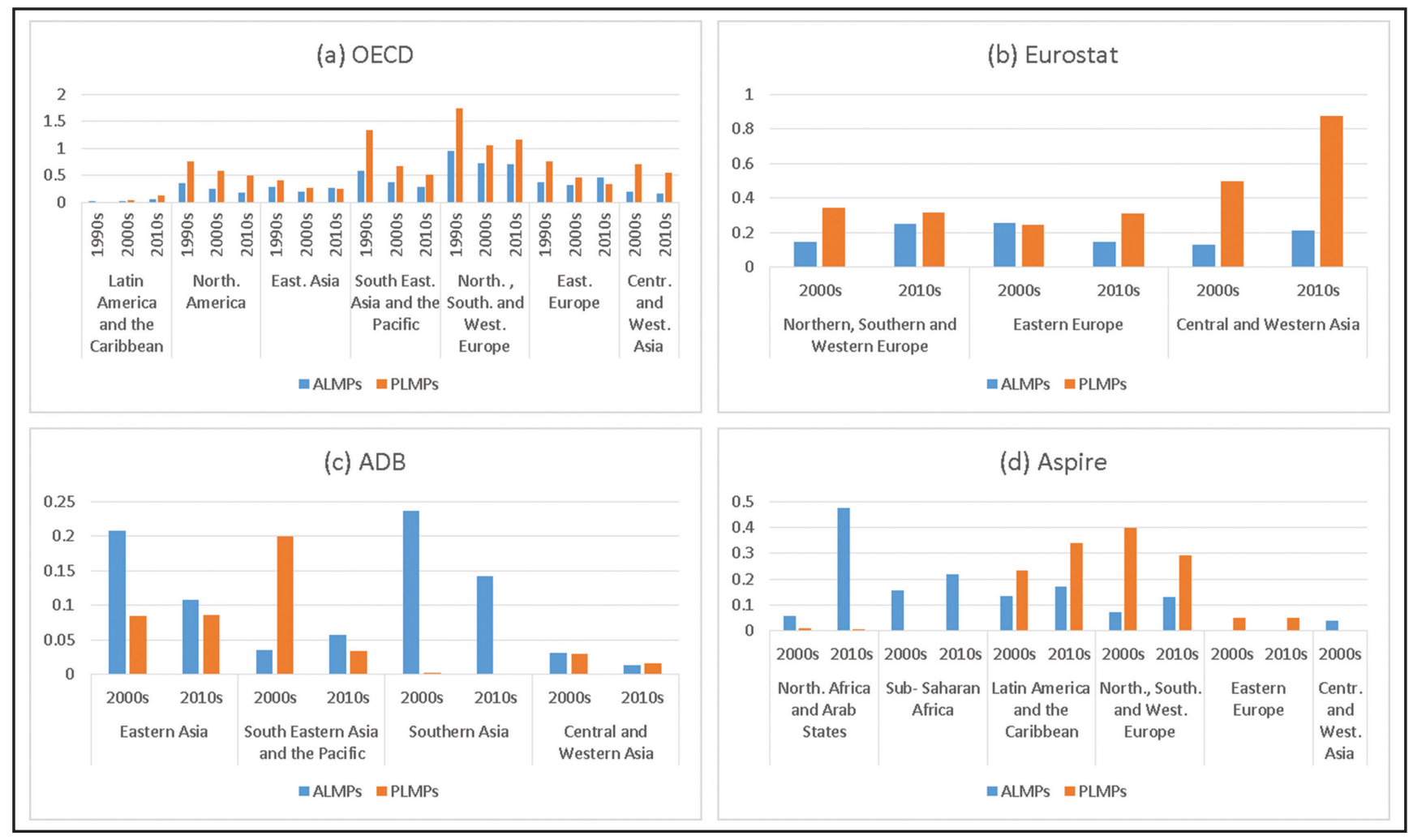

Note: Authors' calculations based on different data sources as reported in Section 2. ALMPs, active labor market policies; PLMPs, passive labor market policies. 
values until 2016. The overall picture is that spending in labor market policies has decreased from initially high levels in all OECD regions; except Latin America and the Caribbean, where it has increased from initially low levels (Panel A). The pattern for emerging and developing economies is reported in the ASPIRE database (Panel D), which shows that spending has increased for all regions apart from Northern, Southern, and Western Europe. For the EU countries outside of the OECD (Panel B), spending has remained relatively stable except Cyprus, where spending has almost doubled. On the other hand, spending has decreased for all Asian regions within the ADB (Panel C).

\section{Empirical strategy}

The purpose of the analysis is to investigate the causal effect of spending in ALMPs and PLMPs (and their interactions) on aggregate employment performances in a panel analysis at the country level. Following previous contributions (Escudero, 2018; Estevão, 2003), we estimate the subsequent model:

$$
Y_{i, t}=c+\beta_{1} L M P_{i, t}+\beta_{2} T_{t}+\beta_{3} C+\varepsilon_{i, t}
$$

Where $Y_{i, t}$ represents the outcome of interest (unemployment, employment or labor force participation rates) in country $i$ and year $t$; $c$ is a constant; $L M P_{i, t}$ is the (vector of) spending in labor market policies; $T_{t}$ are year fixed effects; $C$ is a linear country indicator; and $\varepsilon_{i, t}$ is the error term.

Apart from the intensity of active and passive policies, labor market outcomes are obviously determined by several other factors. We are fairly limited by data availability - especially for the emerging and developing economies in our sample - and many of the controls used in previous contributions are less informative in our setting, as labor market institutions are often less binding in emerging and developing economies due to lower compliance with labor law. We compensate for this lack in control variables by including year-fixed effects and a linear country control. This allows us to control for time-variant shocks that affect all countries in the same way and time-invariant differences at the country level. Using a robustness analysis (as reported in Section 6.2.), we will include a series of control variables that are available for the full sample. For now, it suffices to say that the inclusion of these controls does not appear to have a significant impact on our findings.

A second issue concerns the choice of the empirical model. The main econometric problem relates to endogeneity due to omitted variable bias or reverse causality, which would directly affect the consistency of the estimated parameters (i.e., Ordinary Least Squares results would be biased). While time and country controls aim to alleviate these concerns, it is impossible to rule out the risk that we are omitting variables that at the same time influence the outcome and the regressors of interest. This is particularly the case given the relatively large sample of countries included, for many of which we lack detailed information on the labor market and institutional characteristics. Concerning the possible risk of reverse causality, it can be expected that when unemployment is high governments decide to increase spending in ALMPs to increase enrollment. ${ }^{7}$ This reverse causality might be even more important for PLMPs, as

7 For instance, the opportunity cost of enrolling in a training program is lower during times of crises due to the reduced job opportunities. 
in this case the level of spending (almost) mechanically increases with the unemployment rate (at least in the majority of developed economies, where this adjustment is in place). To control for these sources of bias, we exploit our rich database and propose a new instrumental variable analysis. Concretely, we estimate the panel models described above by instrumenting the expenditure in ALMPs and PLMPs (or their interactions) with their source, in the spirit of what has previously been done in the micro-econometric literature to account for measurement error in educational levels (Ashenfelter and Rouse, 1998).

The rationale behind this instrumental variable strategy is that each of the different sources we consulted to create our database applies slightly different definitions, calculation methods, and inclusion criteria. This clearly raises potential problems of measurement error. At the same time, the source of the spending data qualifies as a potentially valid instrument given that it will be correlated with the level of spending (first stage relationship) without being otherwise correlated with the outcome of interest (exclusion restriction). Indeed, the outcome data is collected from the WESO database, regardless of the source used to collect the spending data. The outcome will therefore be uncorrelated to the instrument. Of course, a possible concern is whether the exclusion restriction is violated if the source of the information is independently correlated with labor market performances (e.g., low-income countries draw their data on spending from a given source, but they are also characterized by worse labor market indicators). We believe that this is not the case, because the different data sources are broad enough to include countries at different levels of economic development. Additionally, we include time and country controls to account for this risk. The downside to this IV strategy is that we cannot include country-fixed effects, as these are perfectly correlated with the instrument. This is why we include a linear control for the country in all specifications. Additionally, the results would still hold after including controls for geographic regions (as introduced above). We present the results of the first- and second-stage IV estimations in what follows. However and given possible concerns on the validity of the instrumental variable approach adopted here, we have also conducted a large set of robustness tests (i.e., including with traditional instrumental variables used in the literature) which confirm the main findings of the analysis and should be read in conjunction with our baseline results.

\section{Overall impact of ALMPs and PLMPs}

This Section will present the main results of the macroeconomic analysis on the impact of overall spending in ALMPs and PLMPs on labor market indicators. In particular, Section 6.1 will present the results of the model outlined above, using both OLS and 2SLS; while Section 6.2 reports a large set of robustness tests.

\subsection{Main results}

As a first step, we will estimate Eq. (1) with OLS. The results are reported in Table 2 below for the unemployment rate, the employment rate, and the labor force participation rate. For each outcome of interest, we present two different specifications: first with spending in active and passive policies and then adding also their interaction. 
Table 2. Results for the unemployment rate, employment-to-population ratio, and labor force participation rate estimated with OLS

\begin{tabular}{|c|c|c|c|c|c|c|}
\hline & (1) & (2) & (3) & (4) & (5) & (6) \\
\hline & \multicolumn{2}{|c|}{ Unemployment rate } & \multicolumn{2}{|c|}{ Employment rate } & \multicolumn{2}{|c|}{ Labor force participation rate } \\
\hline \multirow[t]{2}{*}{ Spending in ALMPs (\% GDP) } & $-0.036^{\star \star \star}$ & $-0.013^{\star \star}$ & $0.054^{\star \star \star}$ & $0.020^{\star \star}$ & $0.035^{\star \star \star}$ & 0.012 \\
\hline & $(0.005)$ & $(0.006)$ & $(0.008)$ & $(0.009)$ & $(0.006)$ & $(0.008)$ \\
\hline \multirow[t]{2}{*}{ Spending in PLMPs (\% GDP) } & $0.032^{\star \star \star}$ & $0.049^{\star \star \star}$ & $-0.029^{\star \star \star}$ & $-0.054^{\star \star \star}$ & $-0.012^{\star \star \star}$ & $-0.029^{\star \star \star}$ \\
\hline & $(0.003)$ & $(0.005)$ & $(0.004)$ & $(0.005)$ & $(0.003)$ & $(0.004)$ \\
\hline \multirow[t]{2}{*}{ Interaction } & & $-0.020^{\star \star \star}$ & & $0.030^{\star \star \star}$ & & $0.021^{\star \star \star}$ \\
\hline & & $(0.004)$ & & $(0.005)$ & & $(0.004)$ \\
\hline \multirow[t]{2}{*}{ Constant } & $0.058^{\star \star \star}$ & $0.044^{\star \star *}$ & $0.540^{\star \star \star}$ & $0.561^{\star \star \star}$ & $0.574^{\star \star \star}$ & $0.588^{\star \star \star}$ \\
\hline & $(0.004)$ & $(0.005)$ & $(0.005)$ & $(0.006)$ & $(0.004)$ & $(0.005)$ \\
\hline Controls & No & No & No & No & No & No \\
\hline Country trend & Yes & Yes & Yes & Yes & Yes & Yes \\
\hline Year FE & Yes & Yes & Yes & Yes & Yes & Yes \\
\hline Observations & 932 & 932 & 932 & 932 & 932 & 932 \\
\hline
\end{tabular}

Note: The presented statistics are coefficient estimates and robust standard errors in parentheses for the panel model outlined in Section 5 .

${ }^{\star \star \star},{ }^{* *},{ }^{*}$ indicate significance at the 1\%, 5\%, 10\% significance level.

ALMPs, active labor market policies; PLMPs, passive labor market policies.

At first glance, we find that additional spending in ALMPs decreases the unemployment rate, while additional spending in PLMPs increases unemployment. This result is expected from a theoretical point of view, as ALMPs are intended to activate the unemployed and help them attain gainful employment (OECD, 2007). PLMPs on the other hand reduce the cost associated with unemployment and increase the reservation wage (Estevão, 2003; Gal and Theising, 2015). In Column 2, we also add the interaction between spending in ALMPs and PLMPs. The results reveal that the interaction between policies significantly decreases the unemployment rate. The results for the employment-to-population ratio and the labor force participation rate are in line with the findings just discussed for the unemployment rate.

Nevertheless, and as stated above, the results from the OLS model are likely to be downward biased given that we cannot exclude any reverse causality. Indeed, while the intensity of spending in labor market policies might affect the respective labor market outcomes, the opposite is also likely to be true (i.e., a higher unemployment rate will likely lead to increased spending in labor market policies). To overcome this issue, we propose a novel IV strategy and instrument the level of spending in each labor market policy by the source of the spending variables. The results of the first-stage equation are reported in Table 3 and show clearly that our first stage holds (i.e., the instruments are significantly correlated with the endogenous regressors). Moreover, the Sanderson-Windmeijer multivariate F-statistic is $>10$ for all three regressors, indicating that there is no problem with weak instruments.

Having established the strength of our instruments, we present the results of our instrumental variable analysis in Table 4 below. While the signs and significance of the coefficients estimated using 2SLS are in line with what was found using OLS, the results of the 2SLS estimations confirm that the coefficients estimated with OLS were indeed downward biased. 
Table 3. Results of the first-stage equation

\begin{tabular}{|c|c|c|c|}
\hline & (1) & (2) & (3) \\
\hline & Spending in ALMPs & Spending in PLMPs & Interaction \\
\hline \multirow[t]{2}{*}{ Eurostat } & $-0.293^{\star \star \star}$ & $-0.325^{\star \star \star}$ & $-0.398^{\star \star \star}$ \\
\hline & $(0.027)$ & $(0.052)$ & $(0.040)$ \\
\hline \multirow[t]{2}{*}{ ADB } & $-0.216^{\star \star \star}$ & $-0.186^{\star \star}$ & $0.191^{\star \star}$ \\
\hline & $(0.046)$ & $(0.079)$ & $(0.096)$ \\
\hline \multirow[t]{2}{*}{ ASPIRE } & 0.413 & $1.101^{\star \star \star}$ & $1.544^{\star \star \star}$ \\
\hline & $(0.081)$ & $(0.159)$ & $(0.211)$ \\
\hline F statistic & 11.29 & 17.36 & 49.01 \\
\hline Observations & 932 & 932 & 932 \\
\hline
\end{tabular}

Note: The presented statistics are coefficient estimates and robust standard errors in parentheses for the first-stage regression of the 2SLS model outlined in Section 5.

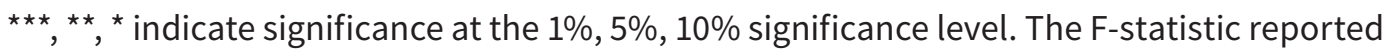
in the Sanderson-Windmeijer multivariate F-statistic.

ALMPs, active labor market policies; ADB, Asian Development Bank; PLMPs, passive labor market policies.

Table 4. Results for the unemployment rate, employment-to-population ratio, and labor force participation rate estimated with 2 SLS

\begin{tabular}{|c|c|c|c|c|c|c|}
\hline & (1) & (2) & (3) & (4) & (5) & (6) \\
\hline & \multicolumn{2}{|c|}{ Unemployment rate } & \multicolumn{2}{|c|}{ Employment rate } & \multicolumn{2}{|c|}{ Labor force participation rate } \\
\hline \multirow[t]{2}{*}{ Spending in ALMPs (\% GDP) } & 0.015 & -0.035 & $0.221^{\star \star}$ & $0.412^{\star \star}$ & $0.230^{\star \star}$ & $0.407^{\star \star}$ \\
\hline & $(0.047)$ & $(0.045)$ & $(0.093)$ & $(0.181)$ & $(0.091)$ & $(0.180)$ \\
\hline \multirow[t]{2}{*}{ Spending in PLMPs (\% GDP) } & 0.018 & $0.092^{\star \star \star}$ & $-0.158^{\star \star \star}$ & $-0.444^{\star \star \star}$ & $-0.149^{\star \star \star}$ & $-0.413^{\star \star \star}$ \\
\hline & $(0.025)$ & $(0.035)$ & $(0.052)$ & $(0.127)$ & $(0.051)$ & $(0.126)$ \\
\hline \multirow[t]{2}{*}{ Interaction } & & $-0.044^{\star \star}$ & & $0.170^{\star \star \star}$ & & $0.157^{\star \star \star}$ \\
\hline & & $(0.018)$ & & $(0.053)$ & & $(0.051)$ \\
\hline \multirow[t]{2}{*}{ Constant } & $0.040^{\star \star \star}$ & $0.031^{\star \star \star}$ & $0.581^{\star \star \star}$ & $0.613^{\star \star \star}$ & $0.605^{\star \star \star}$ & $0.635^{\star \star \star}$ \\
\hline & $(0.008)$ & $(0.009)$ & $(0.016)$ & $(0.024)$ & $(0.014)$ & $(0.023)$ \\
\hline Controls & No & No & No & No & No & No \\
\hline Country trend & Yes & Yes & Yes & Yes & Yes & Yes \\
\hline Year FE & Yes & Yes & Yes & Yes & Yes & Yes \\
\hline Observations & 932 & 932 & 932 & 932 & 932 & 932 \\
\hline
\end{tabular}

Note: The presented statistics are coefficient estimates and robust standard errors in parentheses for the panel model outlined in Section 5. The spending in ALMPs and spending in PLMPs variables are instrumented by its source.

${ }^{\star \star *},{ }^{* \star},{ }^{*}$ indicate significance at the $1 \%, 5 \%, 10 \%$ significance level.

ALMPs, active labor market policies; PLMPs, passive labor market policies.

As above, the inclusion of the interaction term reveals how PLMPs might have detrimental effects if implemented in isolation. However, the interaction between active and passive interventions is positive and statistically significant for both the labor force participation rate and the employment rate - meaning that both types of interventions can have a positive labor market effect provided that enough is spent in the other type of policy. In terms of magnitude, for any given value of spending in PLMPs (ALMPs) $x$, the effect of an additional 
unit (here, 1\% of GDP) spent in ALMPs (PLMPs) is equal to $-0.035-0.044 \times(0.092-0.044 \times)$. In other words, the point estimate of the impact of either labor market policy change gradually when the spending in the other type of intervention increases. So while spending in PLMPs increases the unemployment rate if the spending in ALMPs is equal to zero, the effect of additional spending in PLMPs turns negative at a certain point. Figure 3 shows

Figure 3. The effect of one additional unit spending on ALMPS (PLMPs) given spending on PLMPs. (a) Unemployment rate. (b) Employment rate.

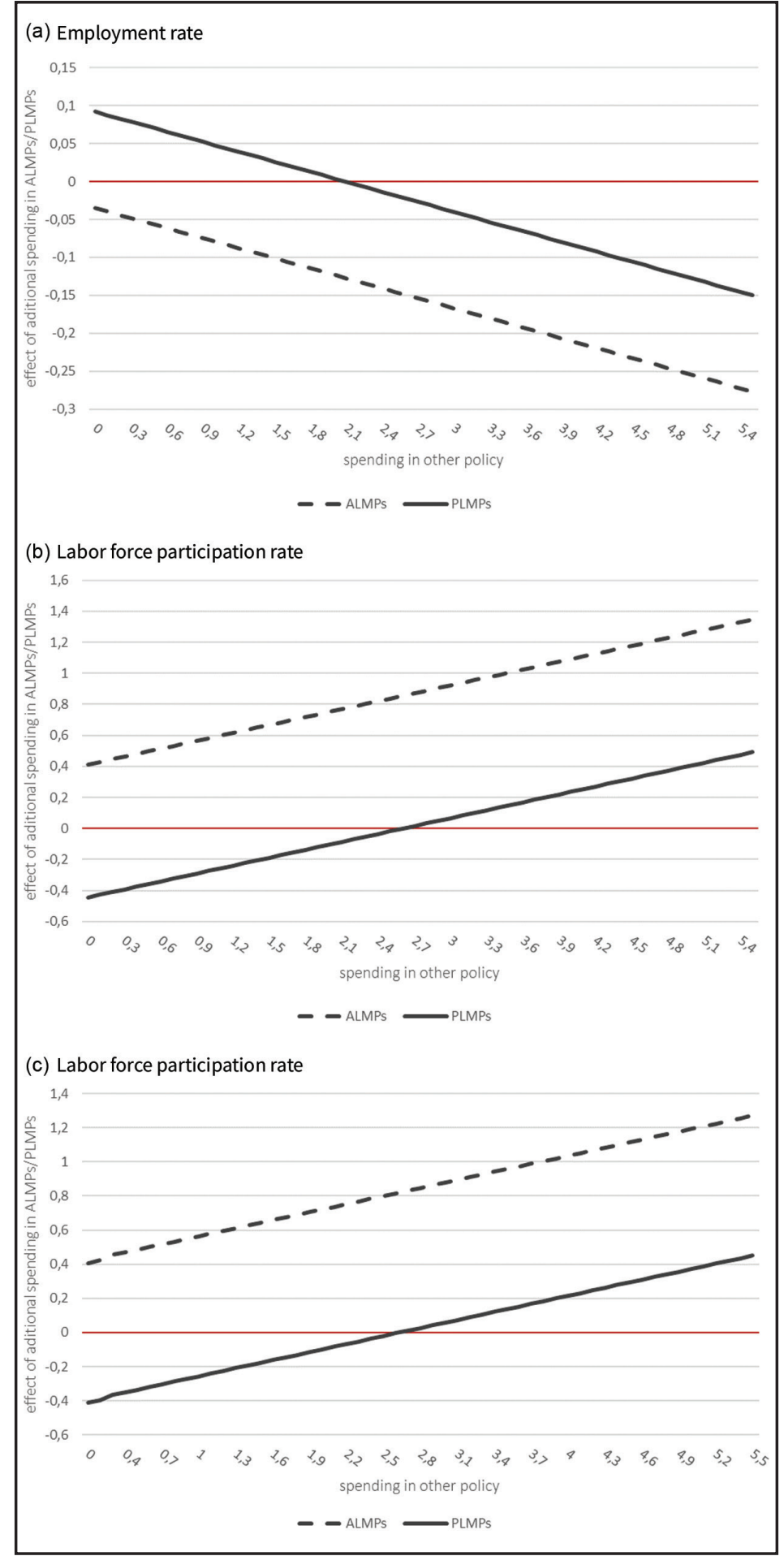

Note: The presented statistics are coefficient estimates for the panel mode outlined in Section 5. ALMPs, active labor market policies; PLMPs, passive labor market policies. 
this more clearly for the three labor market outcomes. Panel A plots the equations quantified here above. The figure confirms that spending in ALMPs decreases unemployment for any level of spending in PLMPs, while spending in PLMPs increases the unemployment rate when spending on the other policy package is zero. For the effect of spending in PLMPs (the full line) the effect turns quickly negative when spending in ALMPs increases (it reaches zero for a level of spending in ALMPs at $2 \%$ of GDP). As a matter of comparison, the median value of spending in ALMPs (PLMPs) in 2014 was equal to 0.16\% (0.34\%) of GDP. This means that spending in ALMPs is beneficial for all countries; while only Denmark currently reaches the threshold level of spending in ALMPs for making spending in PLMPs beneficial to unemployment reduction (Denmark had in 2014 a value of spending in ALMPs just above $2 \%$ of GDP).

For the employment and labor force participation rates, the critical thresholds of spending is higher than for the case of the unemployment rate. In particular, spending in PLMPs improves these outcomes provided that around 2.5\% of GDP is spent in ALMPs, meaning that currently, no country reaches this threshold.

\subsection{Robustness tests}

First, recall that our main specifications do not include any control variables other than year-fixed effects and a linear country indicator. If there are variables that influence our outcomes of interest and are correlated with our main regressors, but are not country-specific and time invariant or time variant but country specific, the results presented above would suffer from omitted variable bias. While we are limited by data availability, we re-estimate our preferred model including several control variables that are available for a large enough part of our sample using a robustness test. In general, the literature has defined four groups of factors possibly influencing labor market outcomes. The first set of factors constitute demand conditions. In this sense, we include the difference between the GDP growth rate and its five-year average to capture cyclical fluctuations. ${ }^{8}$ While Escudero (2018) controls for the terms of trade, this data is not available for our entire sample. The second set of factors deals with the structure of the labor market. For instance, Escudero (2018) controls for this by including the share of the population on a certain skill level. We follow this contribution by including the share of employment in low and medium skills occupations (with high skills occupations acting as the reference category) - as obtained by the ILO WESO database. A final set of determinants are fiscal measures. In line with Gal and Theising (2015), we include the governments' primary balance to make sure that the measured effects of active and passive policies do not result from an overall fiscal stimulus. Estevão (2003) and Gal and Theising (2015) control in addition to the level of government employment, data which is nevertheless not available for our sample. ${ }^{9}$ Table 5 presents the results of our preferred 2SLS

8 Ideally, we would include the output gap as is done by Gal and Theising (2015) and Elmeskov et al. (1998) but these data are not available for all countries in our sample.

9 Existing studies have also included a number of controls related to labor market institutions (e.g., trade union coverage, tax wedge, and prevalence of minimum wages). However, these variables are not available from a comparable data source for the countries included in the analysis and they would anyhow be less informative in settings characterized by high informality rates and low enforcement of labor legislation. 
Table 5. Results for the robustness test including additional controls

\begin{tabular}{|c|c|c|c|c|c|c|}
\hline \multirow[b]{3}{*}{ Spending in ALMPs (\% GDP) } & (1) & (2) & (3) & (4) & (5) & (6) \\
\hline & \multicolumn{2}{|c|}{ Unemployment rate } & \multicolumn{2}{|c|}{ Employment rate } & \multicolumn{2}{|c|}{ Labor force participation rate } \\
\hline & -0.022 & -0.070 & $0.337^{\star}$ & 0.558 & $0.323^{\star}$ & 0.531 \\
\hline & $(0.073)$ & $(0.078)$ & $(0.180)$ & $(0.342)$ & $(0.172)$ & $(0.331)$ \\
\hline \multirow[t]{2}{*}{ Spending in PLMPs (\% GDP) } & 0.037 & $0.121^{\star \star}$ & $-0.196^{\star \star}$ & $-0.587^{\star \star \star}$ & $-0.173^{\star \star}$ & $-0.540^{\star \star \star}$ \\
\hline & $(0.035)$ & $(0.050)$ & $(0.090)$ & $(0.199)$ & $(0.086)$ & $(0.191)$ \\
\hline \multirow[t]{2}{*}{ Interaction } & & $-0.049^{\star}$ & & $0.226^{\star \star \star}$ & & $0.212^{\star \star \star}$ \\
\hline & & $(0.026)$ & & $(0.078)$ & & $(0.073)$ \\
\hline \multirow[t]{2}{*}{ Constant } & -0.022 & -0.070 & $0.337^{\star}$ & 0.558 & $0.323^{\star}$ & 0.531 \\
\hline & $(0.073)$ & $(0.078)$ & $(0.180)$ & $(0.342)$ & $(0.172)$ & $(0.331)$ \\
\hline Controls & Yes & Yes & Yes & Yes & Yes & Yes \\
\hline Country trend & Yes & Yes & Yes & Yes & Yes & Yes \\
\hline Year FE & Yes & Yes & Yes & Yes & Yes & Yes \\
\hline Observations & 871 & 871 & 871 & 871 & 871 & 871 \\
\hline
\end{tabular}

Note: The presented statistics are coefficient estimates and robust standard errors in parentheses for the robustness analysis outlined in Section 6.2. The spending on ALMPs and spending on PLMPs variables are instrumented by its source.

${ }^{\star \star \star},{ }^{\star \star *},{ }^{*}$ indicate significance at the $1 \%, 5 \%, 10 \%$ significance level

ALMPs, active labor market policies; PLMPs, passive labor market policies.

model including the controls which are available for a sufficiently large part of our sample. It is clear that adding these extra control variables does not seem to significantly impact our main findings. These results give some reassurance that the baseline specification does not suffer from omitted variable bias.

The majority of the existing literature relies on the lagged value of spending in labor market policies as an instrument to overcome reverse causality. Indeed, it can be argued that current unemployment rates can influence spending levels but past spending is not impacted by current unemployment rates. Nevertheless, this instrumental variable strategy has been criticized, as current unemployment rates are highly correlated with past unemployment rates, which are in themselves correlated with the spending variables, violating the exclusion restriction crucial to any IV estimation. While we believe that the novel instrument used throughout this paper is an improvement over the previous contributions, there are still concerns for identification. For this reason, we conduct a series of robustness tests. First, we re-estimate our 2SLS model with the lagged spending as instruments. The results of this exercise are reported in Table 6. While most results are in line with what we found in the main analyses, we see that isolated spending in ALMPs has negative labor market consequences in the most complete specifications (i.e., additional spending in ALMPs increases unemployment and decreases employment and labor force participation).

Apart from the endogeneity issues discussed above, panel data are likely to be plagued by serial correlation in the idiosyncratic error term (Escudero, 2018; Lusinyan and Bonato, 2007). Although this does not necessarily affect identification, it would definitely influence inference (i.e., estimated coefficients would be consistent but not efficient). To test for this autocorrelation, we use the Arellano-Bond post-estimation technique (Roodman, 2009). Given that this 
Table 6. Results for the robustness test using the lagged value of spending as an instrument

\begin{tabular}{|c|c|c|c|c|c|c|}
\hline & (1) & $(2)$ & (3) & (4) & (5) & (6) \\
\hline & \multicolumn{2}{|c|}{ Unemployment rate } & \multicolumn{2}{|c|}{ Employment rate } & \multicolumn{2}{|c|}{ Labor force participation rate } \\
\hline \multirow[t]{2}{*}{ Spending in ALMPs (\% GDP) } & $-0.016^{\star \star}$ & $0.033^{\star \star \star}$ & 0.011 & $-0.026^{\star \star \star}$ & 0.003 & -0.006 \\
\hline & $(0.008)$ & $(0.010)$ & $(0.008)$ & $(0.010)$ & $(0.005)$ & $(0.006)$ \\
\hline \multirow[t]{2}{*}{ Spending in PLMPs (\% GDP) } & $0.044^{\star \star \star}$ & $0.085^{\star \star \star}$ & $-0.028^{\star \star \star}$ & $-0.059^{\star \star \star}$ & -0.002 & $-0.010^{\star \star}$ \\
\hline & $(0.005)$ & $(0.007)$ & $(0.004)$ & $(0.006)$ & $(0.003)$ & $(0.005)$ \\
\hline \multirow[t]{2}{*}{ Interaction } & & $-0.037^{\star \star \star}$ & & $0.028^{\star \star \star}$ & & $0.007^{\star \star}$ \\
\hline & & $(0.005)$ & & $(0.005)$ & & $(0.003)$ \\
\hline \multirow[t]{2}{*}{ Constant } & $0.131^{\star \star \star}$ & $0.077^{\star \star \star}$ & $0.621^{\star \star \star}$ & $0.663^{\star \star \star}$ & $0.703^{\star \star \star}$ & $0.714^{\star \star \star}$ \\
\hline & $(0.022)$ & $(0.024)$ & $(0.024)$ & $(0.026)$ & $(0.019)$ & $(0.020)$ \\
\hline Controls & No & No & No & No & No & No \\
\hline Country trend & Yes & Yes & Yes & Yes & Yes & Yes \\
\hline Year FE & Yes & Yes & Yes & Yes & Yes & Yes \\
\hline Observations & 803 & 803 & 803 & 803 & 803 & 803 \\
\hline
\end{tabular}

Note: The presented statistics are coefficient estimates and robust standard errors in parentheses for the robustness analysis outlined in Section 6.2. The spending on ALMPs and spending on PLMPs variables are instrumented by its lagged values.

${ }^{\star \star \star},{ }^{\star *},{ }^{*}$ indicate significance at the $1 \%, 5 \%, 10 \%$ significance level.

ALMPs, active labor market policies; PLMPs, passive labor market policies.

test confirms the presence of first-order autocorrelation (AR(1)), we estimate the model using feasible generalized least squares (FGLS). FGLS is a viable alternative to OLS as it allows for the presence of $\mathrm{AR}(1)$ autocorrelation within panels and cross-sectional correlation and heteroskedasticity across panels (Escudero, 2018). The results are available from the authors upon request and they are in line with those discussed above. A final concern is that our results are disproportionately driven by the economic crisis of 2008 and its aftermath. This might be a general concern but is even more the case in our sample, where the data for developing countries specifically is fairly recent and, as a result, the crisis years count for an important share of the evidence for these countries. To test for this, we exclude the years from 2008 onwards. The results of this exercise are reported in Table 7 . While we clearly lose some precision in the point estimates, neither the sign nor the size of the effects seems to be impacted by the exclusion of the crisis years.

\section{Effects by country groups}

The section above has presented evidence on the overall effectiveness of ALMPs and PLMPs (i.e., globally conceived), pooling data from developed, developing, and emerging nations. Nevertheless, labor market institutions, as well as the use and implementation of labor market policies, are very different between groups of countries. Moreover, due to data limitations, the existing research so far has been mainly focused on the effect of spending in labor market policies on labor market outcomes in developed countries. While the results presented in the previous section show that these overall results hold when including emerging and developing 
Table 7. Results for the robustness test excluding the crisis years

\begin{tabular}{|c|c|c|c|c|c|c|}
\hline \multirow[b]{3}{*}{ Spending in ALMPs (\% GDP) } & (1) & (2) & (3) & (4) & (5) & (6) \\
\hline & \multicolumn{2}{|c|}{ Unemployment rate } & \multicolumn{2}{|c|}{ Employment rate } & \multicolumn{2}{|c|}{ Labor force participation rate } \\
\hline & 0.071 & 0.050 & 0.206 & 0.539 & $0.240^{*}$ & 0.587 \\
\hline & $(0.083)$ & $(0.068)$ & $(0.138)$ & $(0.386)$ & $(0.132)$ & $(0.395)$ \\
\hline \multirow[t]{2}{*}{ Spending in PLMPs (\% GDP) } & 0.004 & 0.025 & $-0.117^{\star \star}$ & $-0.442^{\star}$ & $-0.112^{\star}$ & $-0.450^{\star}$ \\
\hline & $(0.036)$ & $(0.055)$ & $(0.059)$ & $(0.252)$ & $(0.057)$ & $(0.257)$ \\
\hline \multirow[t]{2}{*}{ Interaction } & & -0.010 & & $0.156^{\star}$ & & $0.162^{\star}$ \\
\hline & & $(0.030)$ & & $(0.093)$ & & $(0.095)$ \\
\hline \multirow[t]{2}{*}{ Constant } & 0.006 & 0.007 & $0.550^{\star \star \star}$ & $0.537^{\star \star \star}$ & $0.554^{\star \star \star}$ & $0.541^{\star \star \star}$ \\
\hline & $(0.018)$ & $(0.016)$ & $(0.031)$ & $(0.056)$ & $(0.029)$ & $(0.057)$ \\
\hline Controls & No & No & No & No & No & No \\
\hline Country trend & Yes & Yes & Yes & Yes & Yes & Yes \\
\hline Year FE & Yes & Yes & Yes & Yes & Yes & Yes \\
\hline Observations & 576 & 576 & 576 & 576 & 576 & 576 \\
\hline
\end{tabular}

Note: The presented statistics are coefficient estimates and robust standard errors in parentheses for the robustness analysis outlined in Section 6.2. The spending on ALMPs and spending on PLMPs variables are instrumented by its source.

***, **, * indicate significance at the $1 \%, 5 \%, 10 \%$ significance level

ALMPs, active labor market policies; PLMPs, passive labor market policies.

countries in the analysis, it is nevertheless interesting to see whether the findings differ by development status. To do this, we re-estimate our preferred model, this time including interactions between the spending variables and a dummy variable which takes the value one if a country is classified as emerging or developing according to the World Bank. The results of these estimations are reported in Table 8.

Firstly, it is apparent from Table 8 that by adding the interactions, we lose some power. Nevertheless, some interesting conclusions can be drawn from these models. Looking at the most complete specifications, we find that spending in ALMPs by itself has a positive influence on the labor market outcomes only in developed countries (except the unemployment rate, where additional spending in ALMPs appears to increase unemployment). For developing countries, the opposite seems to be the case. In other words, spending in ALMPs increases unemployment and lowers employment and labor force participation in developing countries when nothing is spent in PLMPs. Isolated spending in PLMPs has the expected effect in developed countries, while it appears to have an ambiguous effect in developing countries (i.e., it increases both unemployment and labor force participation). This is in line with the expectation that classical concerns over the job-search disincentive effects of passive support might be less relevant in countries characterized by high out-of-work poverty rates. Finally, the interaction between both policies takes on the expected sign in both developed and developing and emerging countries. Additionally, there is suggestive evidence that the interaction between ALMPs and PLMPs is more effective in developing and emerging than developed countries. In particular, the coefficient of the interaction between ALMPs and PLMPs and the dummy for developing countries is negative for the unemployment rate 
Table 8. Results for the heterogeneity analysis by development status estimated using 2SLS

\begin{tabular}{|c|c|c|c|c|c|c|}
\hline \multirow{3}{*}{ Spending in ALMPs (\% GDP) } & \multirow{2}{*}{\multicolumn{2}{|c|}{$\frac{(1)}{\text { Unemployment rate }}$}} & \multirow{2}{*}{\multicolumn{2}{|c|}{$\frac{(3) \quad(4)}{\text { Employment rate }}$}} & \multirow{2}{*}{\multicolumn{2}{|c|}{$\frac{(5)}{\text { Labor force participation rate }}$}} \\
\hline & & & & & & \\
\hline & $0.105^{\star \star}$ & $0.136^{\star \star \star}$ & \multicolumn{2}{|c|}{$0097 \quad 0216^{* *}$} & \multirow{2}{*}{$\begin{array}{l}0.175^{\star \star} \\
(0.072)\end{array}$} & \multirow{2}{*}{$\begin{array}{l}0.276^{\star \star} \\
(0.124)\end{array}$} \\
\hline & $(0.041)$ & $(0.042)$ & $(0.065)$ & $(0.108)$ & & \\
\hline \multirow[t]{2}{*}{ Spending in PLMPs (\% GDP) } & -0.036 & -0.001 & $-0.093^{\star \star}$ & $-0.301^{\star \star \star}$ & $-0.127^{\star \star \star}$ & $-0.319^{\star \star \star}$ \\
\hline & $(0.023)$ & $(0.030)$ & $(0.043)$ & $(0.087)$ & $(0.046)$ & $(0.096)$ \\
\hline \multirow[t]{2}{*}{ Interaction } & & -0.024 & & $0.137^{\star \star \star}$ & & $0.133^{\star \star \star}$ \\
\hline & & $(0.020)$ & & $(0.039)$ & & $(0.043)$ \\
\hline \multirow[t]{2}{*}{ Spending in ALMPs x Developing } & -0.072 & -0.041 & $-0.214^{\star \star \star}$ & $-0.408^{\star \star \star}$ & $-0.278^{\star \star \star}$ & $-0.437^{\star \star \star}$ \\
\hline & $(0.046)$ & $(0.045)$ & $(0.071)$ & $(0.118)$ & $(0.079)$ & $(0.136)$ \\
\hline \multirow[t]{2}{*}{ Spending in PLMPs x Developing } & $0.159^{\star \star \star}$ & $0.243^{\star \star \star}$ & -0.031 & 0.106 & 0.054 & $0.214^{\star}$ \\
\hline & $(0.035)$ & $(0.053)$ & $(0.051)$ & $(0.107)$ & $(0.052)$ & $(0.116)$ \\
\hline \multirow[t]{2}{*}{ Interaction x Developing } & & $-0.631^{\star \star \star}$ & & 0.264 & & 0.026 \\
\hline & & $(0.186)$ & & $(0.193)$ & & $(0.156)$ \\
\hline \multirow[t]{2}{*}{ Constant } & $0.046^{\star \star \star}$ & 0.046 & $0.648^{\star \star \star}$ & $0.678^{\star \star \star}$ & $0.722^{\star \star \star}$ & $0.741^{\star \star \star}$ \\
\hline & $(0.008)$ & $(0.031)$ & $(0.068)$ & $(0.105)$ & $(0.074)$ & $(0.114)$ \\
\hline Controls & No & No & No & No & No & No \\
\hline Country trend & Yes & Yes & Yes & Yes & Yes & Yes \\
\hline Year FE & Yes & Yes & Yes & Yes & Yes & Yes \\
\hline Observations & 932 & 932 & 932 & 932 & 932 & 932 \\
\hline
\end{tabular}

Note: The presented statistics are coefficient estimates and robust standard errors in parentheses for the robustness analysis outlined in Section 6.2. The spending on ALMPs and spending on PLMPs variables are instrumented by its source.

${ }^{* \star *},{ }^{* \star},{ }^{*}$ indicate significance at the 1\%, 5\%, 10\% significance level ALMPs, active labor market policies; PLMPS, passive labor market policies.

and positive for employment and labor force participation rates. In the case of the unemployment rate, the coefficient is also statistically significant.

We replot the same figures as presented in Section 6 for developed and developing and emerging countries separately. It is again important to note that we lose some power by adding the interaction term, and therefore some of these results need to be interpreted carefully. Figure 4 shows the results for the developed countries in our sample. While the effects are in line with the findings for the overall sample when looking at the employment-to-population ratio and the labor force participation rate, the same does not hold for the unemployment rate. In fact, the results for the unemployment rate are the opposite of what we found for the full sample, and, as a result, counterintuitive. It is nevertheless important to note that neither the effect of spending in PLMPs nor the interaction is significantly different from zero. When considering the developing and emerging countries as presented in Figure 5, we find that both ALMPs and PLMPs have detrimental labor market effects in isolation. These effects nevertheless become quickly positive when spending in the other policy package increases. This indicates that for developing and emerging countries, it seems even more important to develop an integrated approach when designing and implementing labor market policies. 
Figure 4. The effect of one additional unit spending on ALMPS (PLMPs) given spending on PLMPs in developed economies.

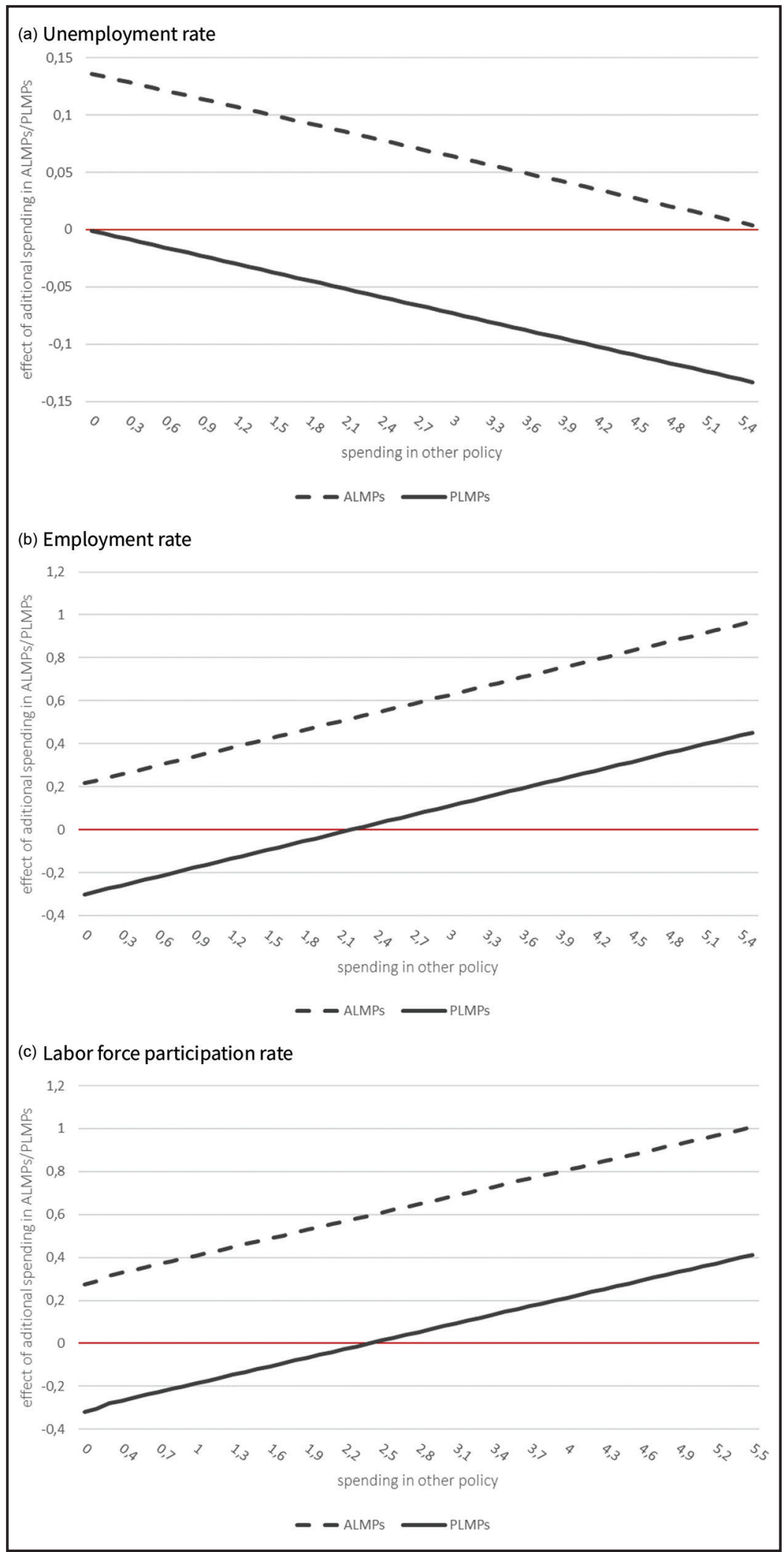

Note: The presented statistics are coefficient estimates for the panel mode outlined in Section 5. ALMPs, active labor market policies; PLMPs, passive labor market policies. 
Figure 5. The effect of one additional unit spending on ALMPS (PLMPs) given spending on PLMPs in emerging and developing economies.

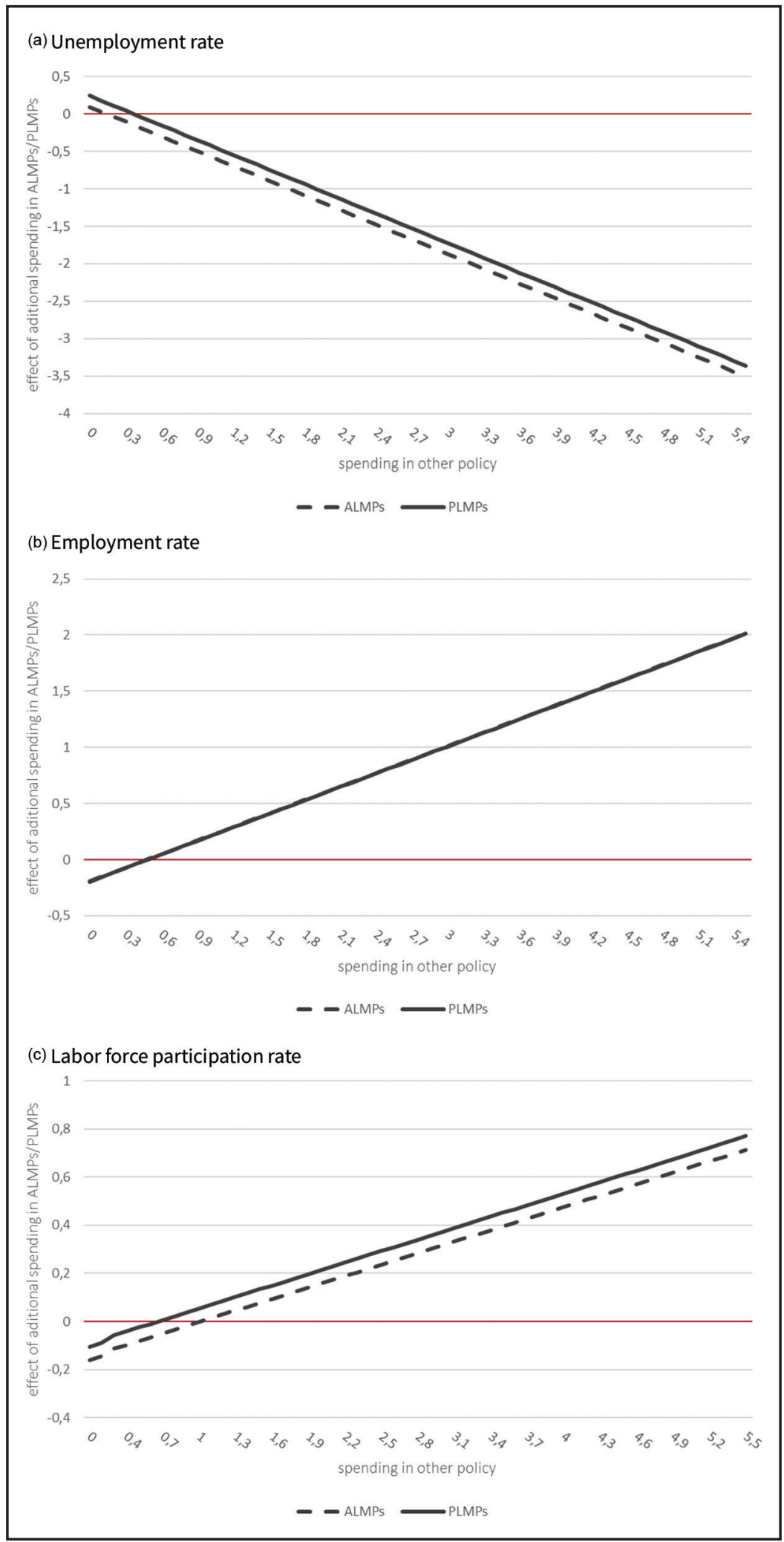

Note: The presented statistics are coefficient estimates for the panel mode outlined in Section 5. The two lines in Panel B almost perfectly overlap. ALMPs, active labor market policies; PLMPs, passive labor market policies. 


\section{Discussion}

The results provided in Sections 6 and 7 show that additional spending in ALMPs results in lower unemployment rates, and higher employment and labor force participation rates. Additional spending in PLMPs on the other hand increases unemployment rates, and lowers employment and labor force participation rates for countries that do not spend anything in ALMPs. Nevertheless, and as shown by the sign and significance of the interaction terms, these effects can change sign if a country spends sufficient amounts in ALMPs - amounts that are currently not reached by any country except Denmark. These conclusions are robust to the use of different estimators (i.e., OLS and FGLS), the inclusion or exclusion of several control variables, the time period under consideration, and - to some extent - the choice of instruments. This leads us to credibly rely on these results (including those by development status), even though the types of countries that enter the analysis largely differ.

While previous studies focused on OECD countries, our findings for a large set of developed, emerging, and developing economies are largely in line with the existing literature, as presented in Section 2. Moreover, the heterogeneity analysis by development status presented in Section 7 shows that the interaction effect between ALMPs and PLMPs is even more important in developing and emerging economies.

These results have important policy implications. Ignoring the interaction effects between ALMPs and PLMPs is detrimental, both from an academic point of view and for policy makers. Indeed, if we would not take the interaction into account, we might conclude that spending in PLMPs leads to negative labor market outcomes and that it, therefore, should be kept limited - and potentially considered as a sunk cost meant to provide support to the unemployed at the expense of labor market efficiency. However, as we learn from our interaction analysis, spending in ALMPs will more effectively ameliorate labor market outcomes if spending in PLMPs is sufficiently high. This can be explained by the fact that participation in active interventions is not attractive (or not effective) if individuals are not provided with adequate income support while being in the activation program. Indeed and especially in developing and emerging economies, individuals cannot afford to spend long periods without a job, and participating in ALMPs (without a source of income) often represents an unaffordable investment whose returns will eventually materialize only in the medium (or even long) run. In this context, any investment in ALMPs alone becomes largely ineffective. Similar reasoning can be made for the spending in PLMPs. Indeed and while it is true that this spending deteriorates labor market outcomes when no money is spent in ALMPs, additional spending in PLMPs becomes beneficial for the labor market once a certain amount is spent in ALMPs. This can be explained by the fact that the provision of income support does not generate disincentive effects when adequate measures are implemented in parallel to activate the unemployed. Rather, guaranteeing income security can increase the efficiency of labor market matching (i.e., higher wages, longer job tenure) if individuals are not forced to accept the first available job in the presence of adequate income support. Of course, the design and implementation of this support are critical to avoid any disincentive effects (e.g., duration, generosity, conditionality). 


\section{Conclusion}

In this paper, we investigate the causal effect of spending in ALMPs and PLMPs on key labor market outcomes in both developed and emerging economies. We do this by means of an IV approach using a rich database containing expenditure information on 121 countries, of which about two-third is non-developed.

We extend the existing literature in two important ways. Firstly, to the best of our knowledge, this is the first contribution that includes observations from non-OECD countries. Indeed, very little evidence exists to show that policies that work well in one labor market context can be easily translated to another context. Furthermore, we explicitly take into account the possible presence of complementarities between ALMPs and PLMPs. This is particularly important given that active and passive policies are often coordinated (if not jointly implemented) and therefore specifications that do not take this interaction into account might suffer from omitted variable bias

We find that the interaction between ALMPs and PLMPs generate substantial beneficial effects in terms of both employment, unemployment, and labor force participation. This means that the more is spent on one type of policy, the more the other policy becomes effective. As a result, even the disincentive effects of PLMPs disappear (and eventually become positive) provided that enough is spent in ALMPs. Moreover, this interaction seems even more important for the developing and emerging countries in our sample.

At the same time, some caveats of the present study need to be kept in mind. First, the analysis looks only at the short-term effects of ALMPs and PLMPs (i.e., the effect of spending in 1 year on labor market outcomes is the same year). However, labor market policies (especially ALMPs) also have substantial medium- and long-term effects, which are not considered in the present analysis. Similarly, we might not capture the overall effect of ALMPs and PLMPs. Indeed, these interventions (especially in developing countries) often have objectives that go beyond the labor market domain (e.g., poverty reduction, social inclusion) that we nevertheless cannot analyze with the available data. Finally, the large number of countries that enter the analysis clearly expands the scope of the present contribution compared to previous studies. At the same time, we need to group together countries that differ on several socio-economic and labor market dimensions that might be difficult to control for within a macro-econometric analysis.

\section{Declarations \\ Competing interests}

The authors declare that they have no competing interests.

\section{Funding}

No particular source of funding is acknowledged.

\section{Authors' contributions}

Not applicable.

\section{Acknowledgments}

We would like to thank Verónica Escudero, Juan Chacaltana and Santo Milasi (ILO), Michele Pellizzari (University of Geneva), and Miguel Ángel Malo (University of Salamanca) for detailed comments as well as seminar participants in Geneva (ILO Research Department BBL seminar) and Ancona (2018 AIEL Meeting) for their insightful feedback. We are very grateful to the ASPIRE team at the World Bank Group for providing access to detailed data on labor market policies as well as to Louise Nennen (ILO) for excellent research assistance. All remaining errors are ours. The views expressed herein are those of the authors and do not necessarily reflect the views of the International Labour Organization. 


\section{References}

Almeida, R. K.; E. Galasso (2010): Jump-Starting Self-Employment? Evidence for Welfare Participants in Argentina. World Development 38(5), 742-755.

Ashenfelter, O.; C. Rouse (1998): Income, Schooling, and Ability: Evidence from A New Sample of Identical Twins. The Quarterly Journal of Economics 113(1), 253-284.

Auer, P.; Ü. Efendioğlu; J. Leschke (2008): Active labour market policies around the world: Coping with the consequences of globalization - Second edition (Geneva, ILO).

Barrientos, A. (2010): Protecting Capability, Eradicating Extreme Poverty: Chile Solidario and the Future of Social Protection. Journal of Human Development and Capabilities 11(4), 579-597.

Barrientos, A.; D. Hulme (2009): Social Protection for the Poor and Poorest in Developing Countries: Reflections on A Quiet Revolution: Commentary. Oxford Development Studies 37(4), 439-456.

Bassanini, A.; R. Duval (2006): Employment Patterns in OECD Countries: Reassessing the Role of Policies and Institutions. OECD Economics Department Working Papers No. 486. OECD Publishing (NJ1).

Bassanini, A.; R. Duval (2009): Unemployment, Institutions, and Reform Complementarities: Re-Assessing the Aggregate Evidence for OECD Countries. Oxford Review of Economic Policy 25(1), 40-59.

Blanchard, O.; J. Wolfers (2000): The Role of Shocks and Institutions in the Rise of European Unemployment: The Aggregate Evidence. The Economic Journal 110(462), C1-C33.

Bolhaar, J.; N. Ketel; B. van Der Klaauw (2019): Job Search Periods for Welfare Applicants: Evidence From A Randomized Experiment. American Economic Journal: Applied Economics 11(1), 92-125.

Boone, J.; J. C. Van Ours (2004): Effective Active Labor Market Policies. SSRN Scholarly Paper ID 641561. Rochester, NY: Social Science Research Network.

Cockx, B.; E. Van Belle (2019): Waiting Longer Before Claiming, and Activating Youth: No Point? International Journal of Manpower 40(4), 658-687.

Crépon, B.; M. Ferracci; D. Fougère (2012): Training the Unemployed in France: How Does it Affect Unemployment Duration and Recurrence? Annals of Economics and Statistics, (107/108), 175-199. doi:10.2307/23646576

DFID. (2011): Cash Transfers. Evidence Paper. DFID, Policy Division.

Elmeskov, J.; J. P. Martin; S. Scarpetta (1998): Key Lessons for Labour Market Reforms: Evidence from OECD Countries' Experience. Swedish Economic Policy Review 5(2), 205-252.

Escudero, V. (2018): Are Active Labour Market Policies Effective in Activating and Integrating Low-Skilled Individuals? An International Comparison. IZA Journal of Labor Policy 7(1), 4.

Escudero, V.; E. L. Mourelo; C. Pignatti (2020): Joint Provision of Income and Employment Support: Evidence from A Crisis Response in Uruguay. World Development 134, 105015.

Estevao, M. M. (2003): Do Active Labor Market Policies Increase Employment? SSRN Scholarly Paper ID 481182. Rochester, NY: Social Science Research Network.

Gal, P.; A. Theising (2015): "The macroeconomic impact of structural policies on labour market outcomes in OECD countries: A reassessment”, OECD Economics Department Working Papers, No. 1271, OECD Publishing, Paris, https://doi.org/10.1787/5jrqc6t8ktjf-en.

Galasso, E.; M. Ravallion; A. Salvia (2004): Assisting the Transition from Workfare to Work: A Randomized Experiment. ILR Review 58(1), 128-142.

Graversen, B. K.; J. C. Van Ours (2008): How to Help Unemployed Find Jobs Quickly: Experimental Evidence From A Mandatory Activation Program. Journal of Public economics 92(10-11), 2020-2035.

Greenberg, D. H.; C. Michalopoulos; P. K. Robins (2003): A Meta-Analysis of Government-Sponsored Training Programs. ILR Review 57(1), 31-53.

Hashemi, S.; R. Rosenberg (2006): Graduating the Poorest into Microfinance: Linking Safety Nets and Financial Services (No. 35823, pp. 1-8). The World Bank.

Heckman, J. J.; R. J. LaLonde; J. A. Smith (1999): The Economics and Econometrics of Active Labor Market Programs, in: Handbook of Labor Economics (Vol. 3, pp. 1865-2097). Elsevier - Amsterdam.

Hujer, R.; P. J. Rodrigues; K. Wolf (2009): Estimating the Macroeconomic Effects of Active Labour Market Policies Using Spatial Econometric Methods. International Journal of Manpower 30(7), 648-671.

ILO. (2012): Social Security for All Building Social Protection Floors and Comprehensive Social Security Systems. Geneva, Switzerland: ILO.

ILO. (2014): World Social Protection Report 2014-15. Geneva, Switzerland: ILO.

ILO. (2016): What Works: Active Labour Market Policies in Latin America and the Caribbean. Geneva, Switzerland: ILO.

ILO. (2019): What Works: Promoting Pathways to Decent Work. Geneva, Switzerland: ILO. 
Kluve, J. (2010): The Effectiveness of European Active Labor Market Programs. Labour Economics 17(6), 904-918.

Lusinyan, L.; L. Bonato (2007): Work Absence in Europe. IMF Staff Papers 54(3), 475-538.

Macours, K.; N. Schady; R. Vakis (2012): Cash Transfers, Behavioral Changes, and Cognitive Development in Early Childhood: Evidence from a Randomized Experiment. American Economic Journal: Applied Economics 4(2), 247-273.

Markussen, S.; K. Røed (2016): Leaving Poverty Behind? The Effects of Generous Income Support Paired with Activation. American Economic Journal: Economic Policy 8(1), 180-211.

Martin, J. P. (2015): Activation and Active Labour Market Policies in OECD Countries: Stylised Facts and Evidence on their Effectiveness. IZA Journal of Labor Policy 4(1), 4.

Martínez, C.; E. Puentes Encina; J. Ruiz-Tagle Venero (2015): Do Micro-Entrepreneurship Programs Increase Wage-Work? Evidence from Chile. Working Paper. University of Chile, Department of Economics.

McCord, A. (2012): Skills Development as Part of Social Protection Programmes. Education for All Global Monitoring Report.

McGuinness, S.; P. J. O'Connell; E. Kelly (2019): Carrots, No Stick, No Driver: The Employment Impact of Job Search Assistance in a Regime with Minimal Monitoring and Sanctions. Journal of Labor Research 40(2), 151-180.

Medina, C.; J. Núñez; J. A. Tamayo (2013): The Unemployment Subsidy Program in Colombia: An Assessment (No. IDB-WP-369). IDB Working Paper Series.

Murtin, F.; A. de Serres (2014): How do Policies Affect the Exit Rate Out of Unemployment? Disentangling Job Creation from Labour Market Frictions. Labour 28(2), 190-208.

Murtin, F.; J. M. Robin (2018): Labor Market Reforms and Unemployment Dynamics. Labour Economics 50, 3-19.

OECD. (1994): The OECD Jobs Study: Facts, Analysis, Strategies. Paris, France: OECD.

OECD. (2007): The OECD Glossary of Statistical Terms. Paris, France: OECD.

Pastore, F.; C. Quintano; A. Rocca (2021): Stuck at a Crossroads? The Duration of the Italian School-To-Work Transition. International Journal of Manpower 42(3), 442-469.

Roodman, D. (2009): How to do Xtabond2: An Introduction to Difference and System GMM in Stata. The Stata Journal 9(1), 86-136.

Sabates-Wheeler, R.; S. Devereux (2011): Transforming Livelihoods for Resilient Futures: How to Facilitate Graduation in Social Protection. FAC Working Paper 23, Brighton: Future Agricultures Consortium. http:// opendocs.ids.ac.uk/opendocs/handle/123456789/2320\#.UpSHc9Lwmys

Van Belle, E.; R. Caers; M. De Couck; V. Di Stasio; S. Baert (2019): The Signal of Applying for a Job Under a Vacancy Referral Scheme. Industrial Relations: A Journal of Economy and Society 58(2), 251-274. 


\section{Appendix}

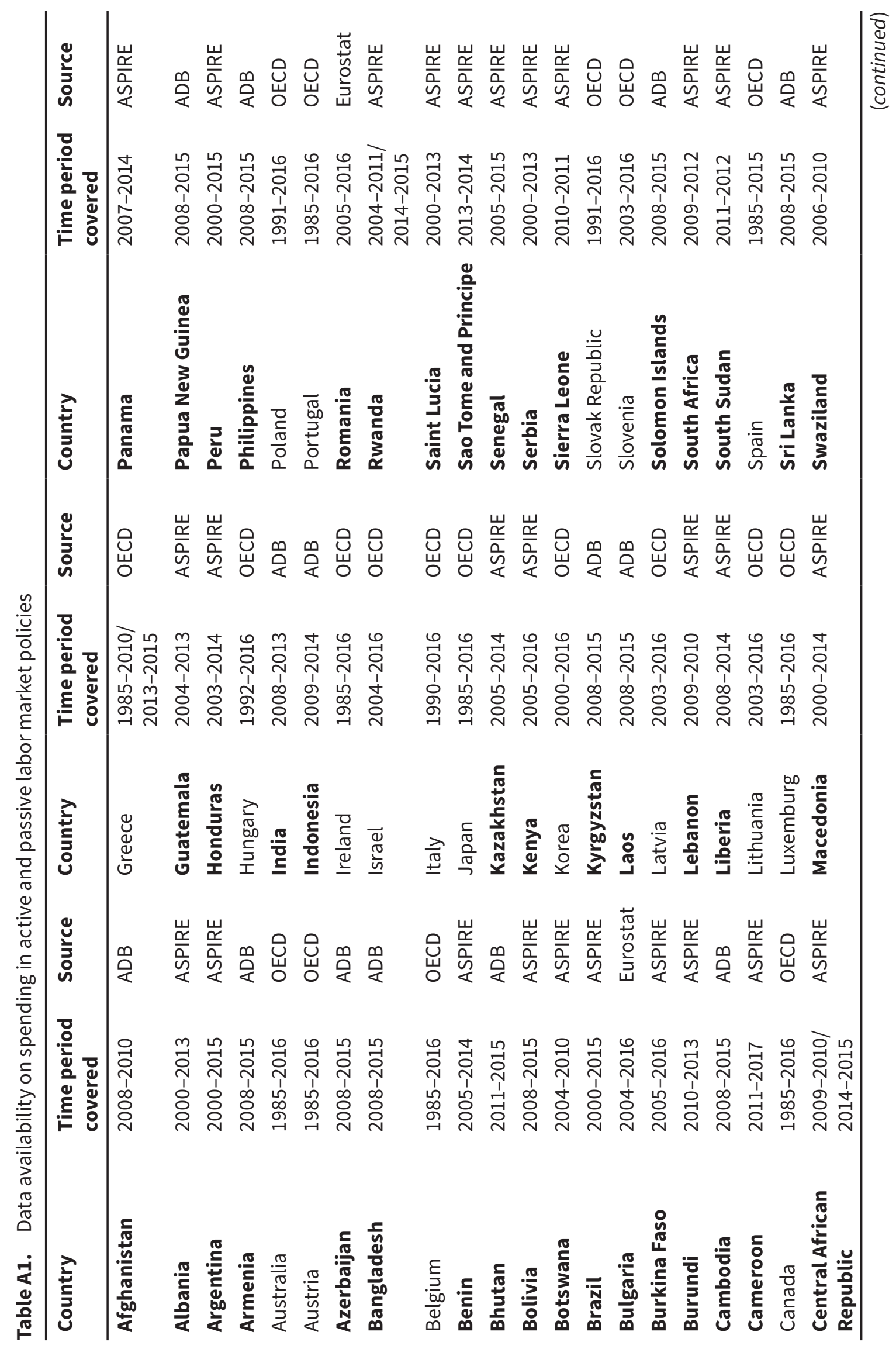




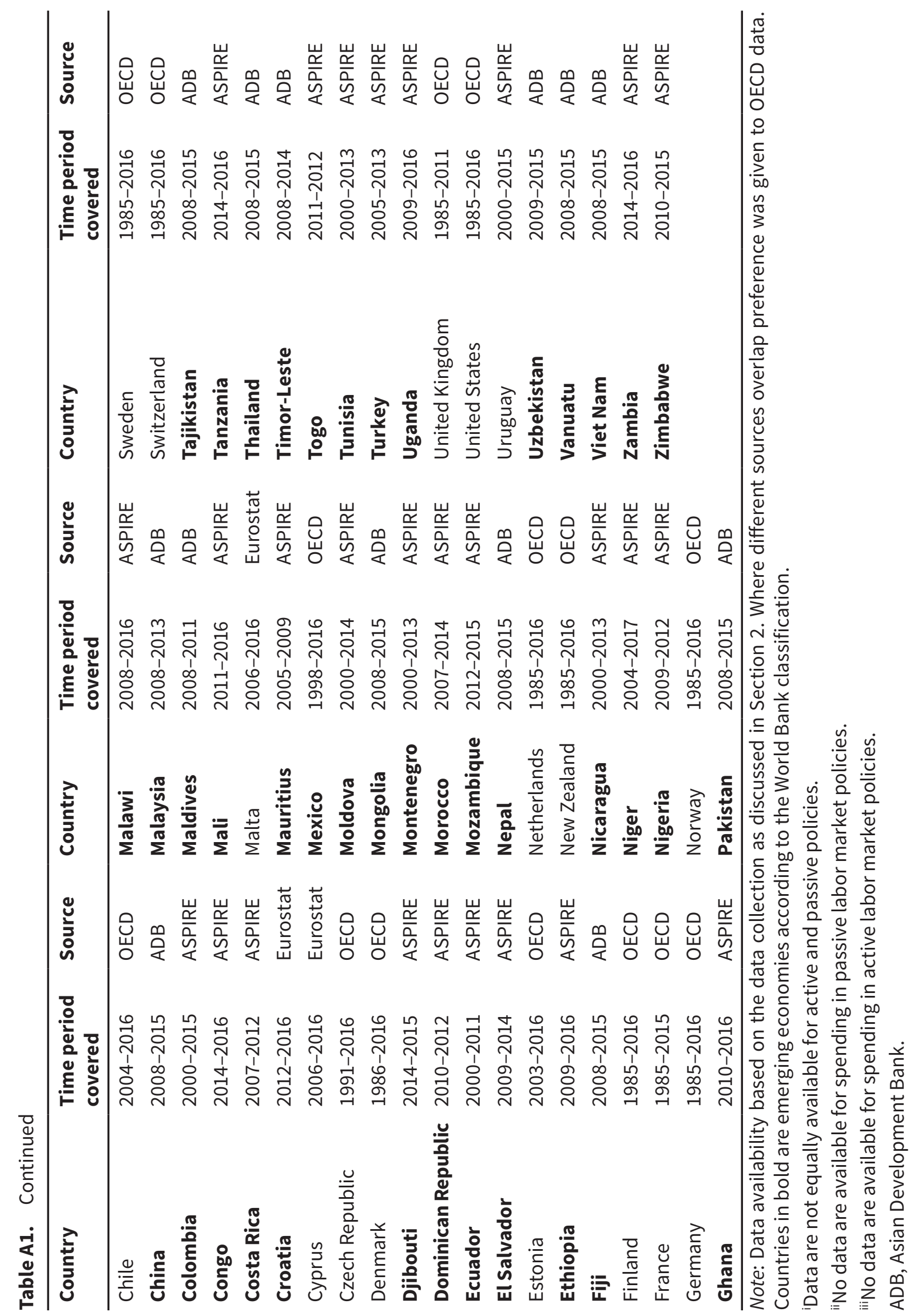

